\title{
Silence as a Tactic of Communication in Pragmatics, Novel, and Poetry
}

\author{
Enas Subhi Amer \\ Department of English, College of Education for Women \\ University of Baghdad, Iraq \\ Adhraa A. Naser \\ Department of English, College of Education for Women \\ University of Baghdad, Iraq \\ Rufaidah Kamal Abdulmajeed \\ Department of English, College of Education for Women \\ University of Baghdad, Iraq
}

\begin{abstract}
This study aims to discuss the meaning of the 'silence' notion pragmatically and literary; in novel and poetry. As far as pragmatics is concerned, it means an important means of communication within a context, and it is a culture dependent. As for silence in literature, it offers the example in which silence is not only present and comprehended but also a substantial part of communication that encapsulate a sender and a receiver. In novels, it is considered as a new humanistic tactic through which a writer would force the reader to feel words rather than reading them plus more intensity and strength. Novelists tend to use silence in writing their novels as it is an integral part of voices and a revelation of so many hidden things, but it mistakenly might be understood as a refusal for communication. Finally, the notion of 'silence' in poetry offers the readers many examples where the poet invites the readers to hear "silence." In some cases, it is even personified and is given a physical being.
\end{abstract}

Keywords: articulation, communication function, pauses, silence, unspeakable

Cites as: Amer, E. S., Andhra A. Naser, A. A. , \& Abdulmajeed, R. K. (2019). Silence as a Tactic of Communication in Pragmatics, Novel, and Poetry. Arab World English Journal for Translation \& Literary Studies, 3 (3) 51-67. DOI: http://dx.doi.org/10.24093/awejtls/vol3no3.4 